\title{
O REFLEXO DA MUDANÇA ORGANIZACIONAL SOBRE O DESEMPENHO DE UMA EMPRESA DE AUTOPEÇAS: UM ESTUDO DE CASO
}

\author{
Francisco Alexandre de Oliveira \\ Departamento de Engenharia de Produção da Universidade Federal de Itajubá - UNIFEI \\ E-mail: aoliveirabr@yahoo.com. Av. BPS, 1303 , Bairro Pinheirinho - Itajubá / MG - CEP: 37500-903
}

\begin{abstract}
Roberto Nunes Duarte
Departamento de Engenharia de Produção da Universidade Federal de Itajubá - UNIFEI E-mail: nnduarte@uol.com.br, Av. BPS, 1303, Bairro Pinheirinho - Itajubá / MG - CEP: 37500-903
\end{abstract}

\author{
Prof. Dr. José Arnaldo Barra Montevechi \\ Departamento de Engenharia de Produção da Universidade Federal de Itajubá - UNIFEI \\ E-mail: arnaldo@iem.efei.br, Av. BPS, 1303, Pinheirinho- Itajubá / MG - CEP: 37500-903
}

\begin{abstract}
Many researchers have developed some studies in the area of change organizational structure. But, there are some questions about this subject. On this way, this article aimed to get a case study about the consequence of organizational change on the performance of a manufacturing industry that was functional and now it has a matricial structure. The industry was broken down in five mini factories with base on its line product and each mini factory is management by a boss with a multiskil group. The firm was evaluated on two aspects: management human resource and quality process. The results show that the quality of products and the organizational enviroment improved.
\end{abstract}

Keywords: organizational framework, human resource, quality.

\section{Introdução}

A utilização dos sistemas de gestão, tais como o JIT (Just in time), Total Quality Management (TQM), ou simplesmente o gerenciamento dos processos com a visão focada no cliente, tem causado grande impacto na estrutura das organizações. Para NETO e FILHO (2000), uma das razões principais para a mudança organizacional das empresas é a busca pela flexibilidade organizacional, que corresponde a capacidade de reação das organizações frente aos sobressaltos impostos pelos movimentos de inovação. No entanto, segundo GONÇALVES (2000), estas mudanças não são fáceis de se conduzir, algumas empresas acabam dando alguns passos e desistem logo depois, sem saber ao certo como prosseguir.

NETO e FILHO (2000) ainda afirmam que há escassez de estudos empíricos abordando a mudança na estrutura das organizações e o reflexo destas mudanças no desempenho da empresa. Deste modo, este artigo apresenta os resultados obtidos com a mudança organizacional em uma indústria do setor de autopeças, fabricante de sistemas e componentes para motores. Nesta empresa, especificamente em uma planta, ocorreu uma profunda mudança na estrutura organizacional, passando de uma estrutura funcional e hierarquizada para uma estrutura mais flexível e uma organização matricial para apoio da área produtiva. O objetivo do artigo é avaliar o reflexo destas mudanças considerando dois aspectos: gestão de recursos humanos e gestão da qualidade do processo. A gestão de recursos humanos se refere ao impacto da nova estrutura organizacional sobre a cultura organizacional existente, principalmente proporcionando maior autonomia aos setores da empresas, gerando um novo ambiente na planta. 


\section{A estrutura das organizações}

A estrutura organizacional pode ser definida, segundo GHANI et al (2002), como a alocação formal de regras de trabalho e mecanismos administrativos para controlar e integrar atividades de trabalho. YAUCH e STEUDEL (2002) afirmam que a estrutura das organizações é fruto da cultura organizacional. Deste modo, a cultura organizacional corresponde a um conjunto de valores que norteiam o comportamento de seus membros, cujo maior objetivo é garantir sua sobrevivência no mercado. CURY (1995) afirma que uma importante ferramenta para análise da estrutura organizacional é uma representação gráfica e abreviada da estrutura da empresa, denominada organograma.

JOHANSON (2000) afirma que a estrutura das organizações, é fortemente influenciada pela estratégia da empresa, ou seja, quando uma decisão estratégica que defini a natureza e direção da organização é formulada, torna-se necessário a adoção de uma estrutura que permita a organização atingir o objetivo previsto. Esta característica da estrutura organizacional foi demonstrada por CHANDLER (1962). Com base em um estudo realizado em empresas norte americanas, CHANDLER (1962) apud CURY afirma que a estrutura da organização é reflexo do comportamento estratégico da empresa frente ao competitividade do mercado no qual está inserida.

\section{Mudança Organizacional}

A mudança é um processo complexo, podendo ser planejada ou simplesmente acontecer. NETO (1999) afirma que as mudanças na estrutura das organizações podem ser de duas naturezas: a mudança não planejada e a mudança planejada ou estratégica. No processo não planejado ou reativo, a organização procura manter um curso firme, solucionando problemas a medida que aparecem. Ao contrário da mudança não planejada, a mudança planejada ou estratégica procura atingir um objetivo estabelecido, e que procura influenciar seus membros. GHANI et al (2002) afirma que a mudança planejada pode ser vista como um esforço proativo da organização, no sentido de envolver seus membros e redefinir suas atividades para atingir um objetivo proposto pela alta administração da organização. YAUCH e STEUDEL (2002) afirmam que existe, dentre outros, três fatores a considerar quando se analisa a mudança organizacional, que são: estimuladores da mudança organizacional; a capacidade da organização em se adaptar a estas mudanças, incluindo as resistências inerentes ao processo; e, principalmente o reflexo destas mudanças no desempenho da organização.

\subsection{Estimuladores da mudança organizacional}

As mudanças que se processam em uma organização, tem como fontes diversos fatores. Deste modo, ALTAMIRANO (1999), ao estudar o processo de mudança organizacional em uma empresa, afirma que os estimuladores de mudanças nas organizações podem ser oriundos da exigência do mercado, avanços tecnológicos ou simplesmente uma atitude estratégica da organização, desencadeada por algum objetivo.

As reações no mercado podem ser representada com a atitude dos clientes cada vez mais preocupados em adquirir produtos com alto valor agregado, assim as empresas tem o desafio de desenvolver novas metodologias de produção ou adotar os sistemas de gestão que possibilitem as sua sobrevivência no mercado. Contudo, tais sistemas exigem uma reestruturação organizacional que permita alcançar os objetivos propostos. Como exemplo, pode-se citar a pesquisa realizada por AHIRE et al (1996). Neste trabalho, os pesquisadores verificaram que ao se utilizar o sistema de gerenciamento total da qualidade (Total Quality Managemen, TQM),com enfoque nas necessidades do cliente, era necessário conduzir uma reestruturação organizacional, ou seja, romper com os métodos tradicionais e gerar um ambiente, onde os empregados fossem favorecidos com programa de autonomia, envolvimento e treinamento. 
GHANI (2002) afirma que o reflexo do avanço da tecnologia de manufatura sobre a estrutura das organizações é um amplo campo de estudo em muitos países. Contudo, o mesmo autor afirma que após adotar uma avançada tecnologia de manufatura, a organização necessita de redefinir funções e tarefas ou, até mesmo eliminar alguns cargos dentro da empresa. O que se pode afirmar, segundo NOORI (1997), é que muitas empresas que possuem uma estrutura tradicional, mecanicista e padronizada não conseguem obter vantagem competitiva ao adotar novas tecnologias porque estas estruturas não possibilitam que seus elementos tenham uma visão proativa em relação ao seu futuro.

GONÇALVES (2000) afirma que os elementos que afetam a estrutura das organizações não atuam de uma forma isolada, mas que cada fator tem uma respectiva correlação com outro. Deste modo, conforme mostra a figura 01, empresa "olha" para o ambiente que a cerca e traduz esta visão para seu ambiente interno, procurando se reorganizar de maneira a responder aos estímulos que recebe.

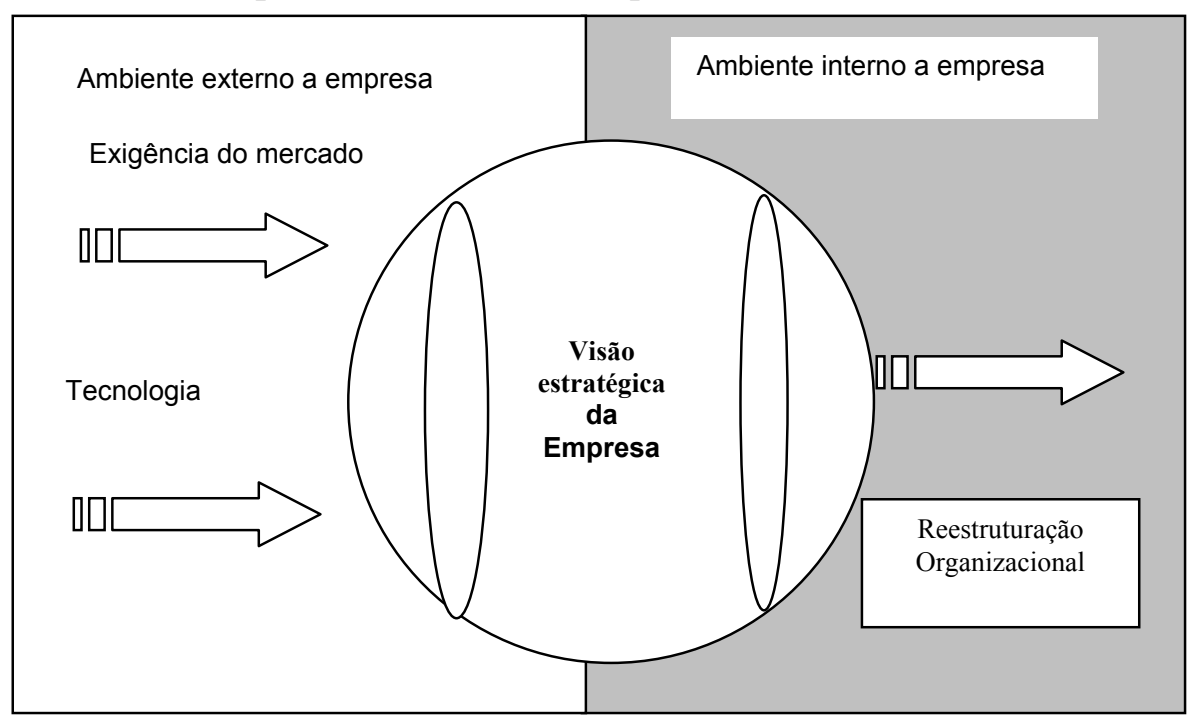

Figura 01-Visão estratégica da empresa frente aos fatores de mudança

\subsection{A resistência a mudança organizacional}

HERNANDEZ e CALDAS (2001) afirmam que uma barreira para a mudança ou inovações dentro das organizações são as resistências as mudanças. Segundo os autores, esta resistência individual passa por sete níveis: o primeiro corresponde a exposição a mudança, o segundo ao processamento inicial, resposta inicial, processamento estendido ou percepção da mudança (coleta de mais informações), aceitação ou resistência emocionais, integração e, finalmente, conclusão ( adoção de comportamento: ativo ou passivo). Contudo, segundo afirma YAUCH et al (2002), o mais importante que isolar os fatores da resistência a mudança é a alta administração adotar planos e estratégias que atenuem a resistência das pessoas a adotar determinada inovação.

\section{Estudo de Caso}

\subsection{A empresa}

A empresa em estudo sofreu várias transformações, partindo de uma companhia familiar, transformando-se em uma multinacional. As mudanças começaram a partir da abertura do mercado nacional de autopeças para importações, como conseqüência o incremento da concorrência entre as várias empresas deste setor. Deste modo, a empresa adotou como alternativa iniciar um processo de melhoria visando reduzir custos e aumentar a competitividade. A segunda grande mudança ocorreu durante o processo sucessório cujo resultado foi a divisão da empresa em três negócios (fundição, sistemas de exaustão e peças para motores e sistemas de suspensão para veículos) e sua venda para um grupo 
nacional da área de fundição e duas multinacionais (Alemã e Italiana) do setor de auto peças. A terceira mudança foi a dissolução da sociedade entre as duas multinacionais e com isto criando a empresa de peças para motores.

Esta nova empresa passou a ser uma divisão de negócios da multinacional alemã que não possuía este tipo de componente em sua linha. Esta aquisição possibilitou a mesma os meios necessários para produzir dentro do grupo um sistema completo pistão/anel/biela/camisa/bronzina para a montagem no motor e conseqüentemente oferecer ao mercado um produto com maior valor agregado. Atualmente esta divisão é composta de duas plantas no Brasil e três no exterior, a planta 1, alvo deste estudo de caso é a maior, com aproximadamente dois mil colaboradores.

A organização da planta 1 era tradicional, com um diretor operacional, gerentes de engenharia, produção, qualidade, recursos humanos e logística. O próximo nível era composto pelos chefes, supervisores, encarregados e líderes. Os setores de compra e controladoria eram corporativos. A antiga estrutura organizacional da planta é mostrada na figura 2, sendo classificada como Estrutura Organizacional Funcional (CURY, 1995).

Com este tipo de estrutura juntamente com a liderança da época, cada departamento operava fechado em si mesmo, ou seja, não existia o espírito de equipe as informações não fluíam entre as áreas administrativas, dava-se grande enfoque ao resultado individual de cada área e não o resultado coletivo da planta. Neste ambiente a autonomia era extremamente cerceada, a rádio "peão" era o instrumento de disseminação das informações e o turnover considerado alto. Como o processo de fabricação sofre influência direta dos colaboradores, os problemas com a qualidade do produto fabricado e refugo estavam aumentando. As conseqüências desta situação poderiam ser observadas através do consumo de recursos com retrabalhos, treinamento de novos colaboradores, queda de produtividade e aumento da estrutura de inspeção, além dos problemas com atrasos de entregas e reclamações de clientes.

\subsection{As mudanças ocorridas na empresa}

Com a criação da diretoria do negócio A e reunião de todas as plantas sob a mesma orientação foi desenhado um plano mestre, diretrizes e metas, visando a coordenação e direcionamento dos esforços da divisão. Em julho de 2001 na planta 1 ocorreu a reestruturação organizacional, criando-se um modelo diferente de gestão em relação ao anterior. Foi elaborado um novo organograma, conforme pode ser visto na figura 3, dividindo-se o setor de produção em áreas de acordo com o tipo de produto fabricado e introduzido o conceito de mini fábricas. Segundo SILVESTRO (2002), quando as empresas reestruturam seu arranjo físico, algum ajuste na estrutura organizacional é necessário. Com base nesta idéia, a nova estrutura organizacional deve conferir a flexibilidade necessária para administrar cada mini fábrica.

Os ajustes na estrutura organizacional começaram com a eliminação da função de diretor operacional, criando-se em seu lugar o de gerente operacional com ligação com os setores de produção, engenharia e manutenção. Quanto aos setores, os setores de qualidade e logística reportam diretamente ao diretor do negócio e o setor de $\mathrm{RH}$ passou a ser corporativo como os setores de compra e controladoria.

O setor de produção foi dividido em cinco mini fábricas e eliminada a figura do gerente de produção, sendo criado o chefe de mini fábrica. A função do chefe de mini fábrica é gerenciar a sua área, através do planejamento e controle da produção, gerenciando o custo, manutenção, qualidade e a engenharia de processo. Com este novo enfoque, o gestor da mini fábrica passou a ter responsabilidade e autoridade tratando a sua área holisticamente, sendo um empreendedor do seu negócio. Para viabilizar esta administração foi criada uma estrutura matricial com as áreas de apoio para cada mini fábrica, conforme mostra a figura 4 . 


\subsection{Análise das mudanças ocorridas na planta 1}

$\mathrm{O}$ processo de mudança começa com o empenho da gerencia em organizar e fomentar o envolvimento e comprometimento de todas as pessoas no processo de mudança. Este foi um dos pontos chaves da reorganização, pois todo processo de mudança gera resistência nas pessoas envolvidas por mudar o seu status quo (HERNANDEZ e CALDAS, 2001) e esta resistência pode significar o fracasso total do projeto. O envolvimento foi conquistado com ações que transmitiram a transparência do processo informando o porquê das mudanças e o que se esperava da equipe após estas transformações. As principais medidas foram fundamentadas no desenvolvimento e valorização do colaborador do piso de fábrica como, por exemplo, uma escola de formação/complementação técnica, plano de cargos e salários, programa de sugestões, abertura do canal de comunicação do operador com o seu chefe e investimento no desenvolvimento dos supervisores.

Um outro ponto fundamental para o sucesso da mudança foi o perfil de liderança e a forma de atuação do diretor e gerente operacional, traçando as metas, orientando e resolvendo os conflitos iniciais. Os chefes também tiveram um papel fundamental no processo fazendo a interface entre as metas traçadas e os colaboradores do piso de fábrica
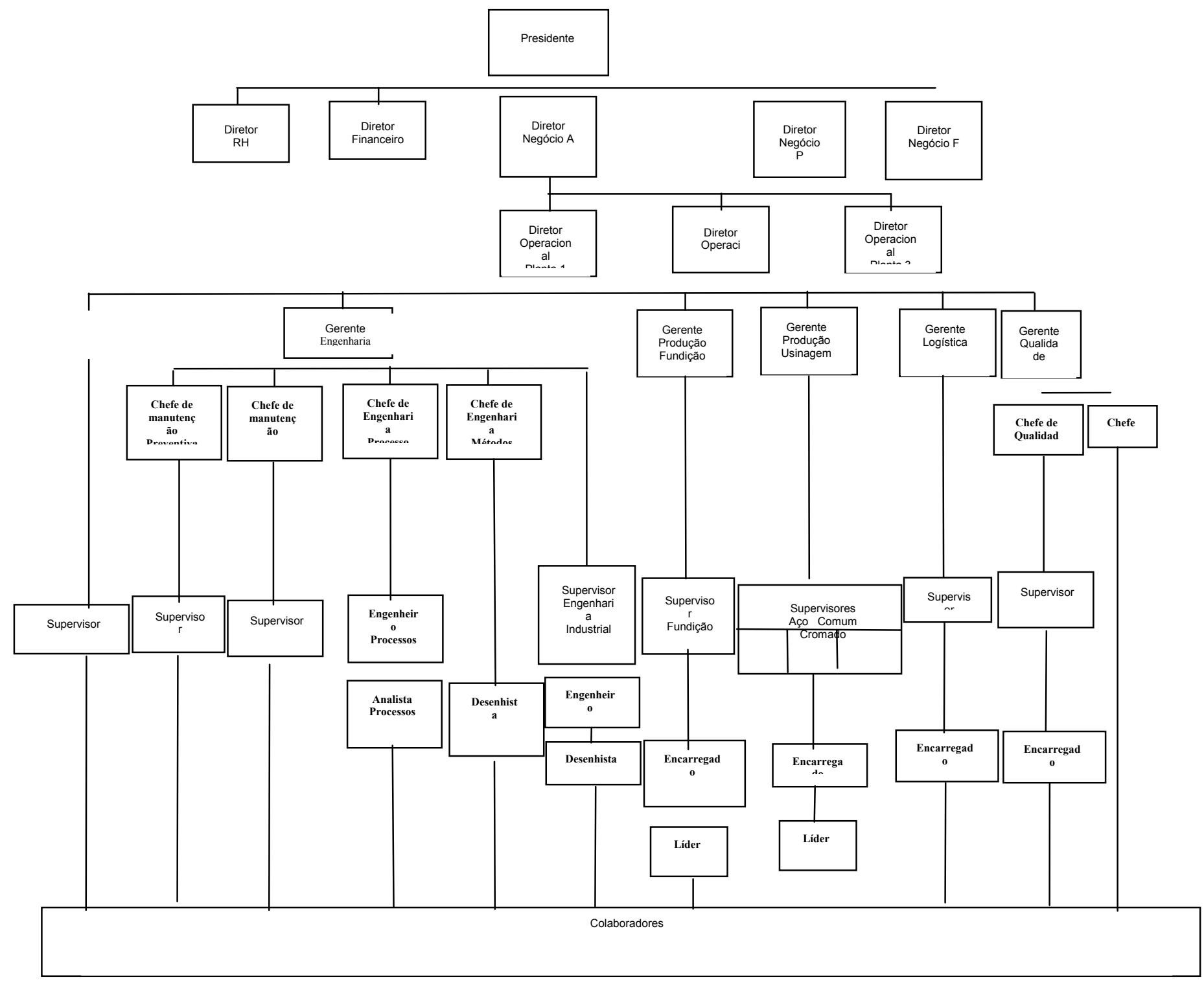

Figura 2 - Organização Funcional da Empresa 


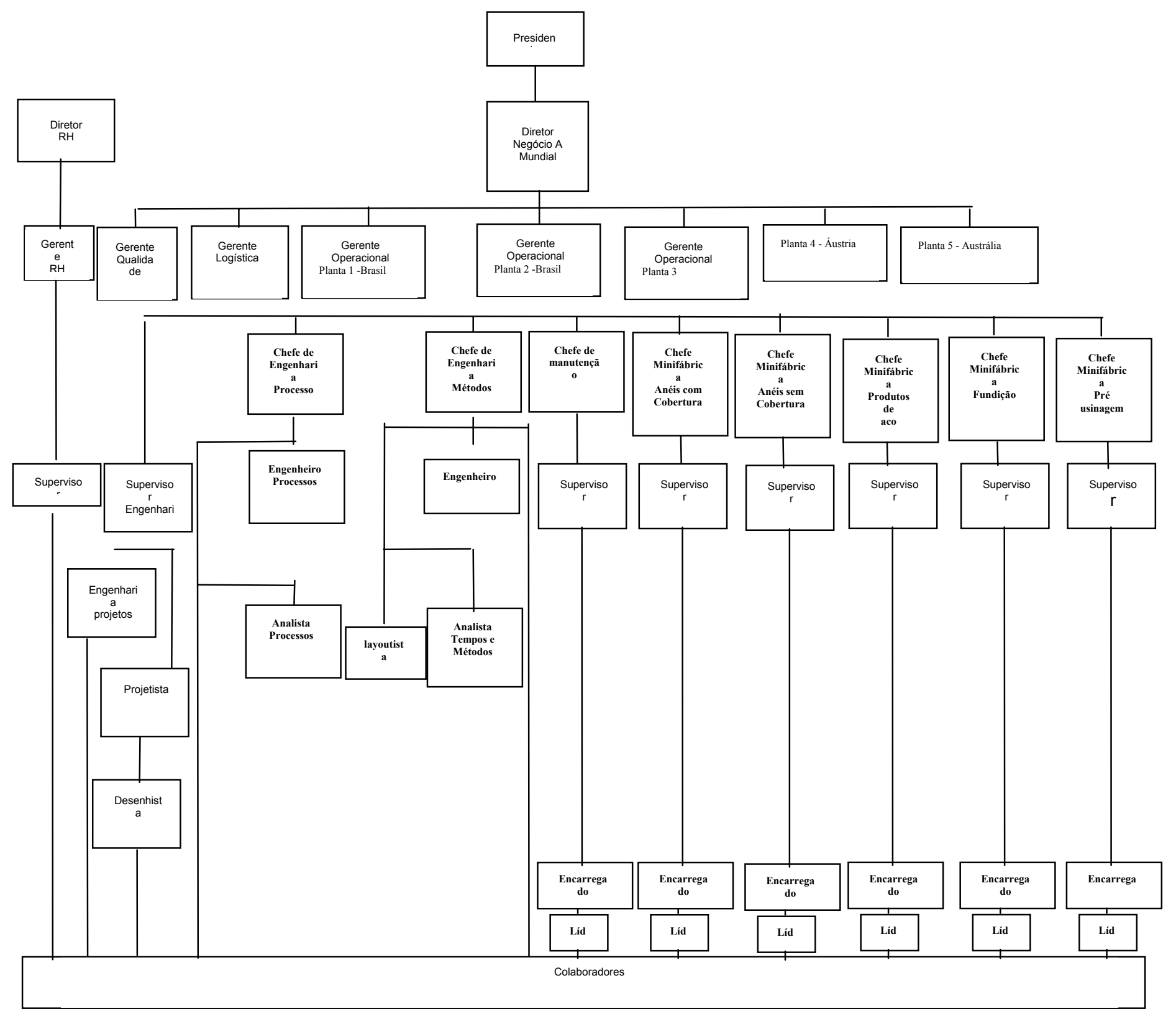

Figura 03 - Estrutura da Organização após reestruturação

\section{OPERAÇÕES}

\begin{tabular}{|c|c|c|c|c|c|} 
& CHEFE 1 & CHEFE 2 & CHEFE 3 & CHEFE 4 & CHEFE 5 \\
\cline { 2 - 7 } & FUNDIÇÃo & $\begin{array}{c}\text { PRE } \\
\text { USINAGEM }\end{array}$ & $\begin{array}{c}\text { ANÉIS SEM } \\
\text { COBERTURA }\end{array}$ & $\begin{array}{c}\text { ANÉIS COM } \\
\text { COBERTURA }\end{array}$ & $\begin{array}{c}\text { PRODUTOS DE } \\
\text { AÇO }\end{array}$ \\
\hline QUALIDADE & Q1 & Q2 & Q3 & Q4 & Q5 \\
\hline PRODUÇÃO & P1 & P2 & P3 & P4 & P5 \\
\hline ENGENHARIA & E1 & E2 & E3 & E4 & E5 \\
\hline LOGISTICA & L1 & L2 & L3 & L4 & L5 \\
\hline MANUTENÇÃO & M1 & M2 & M3 & M4 & M5 \\
\hline $\begin{array}{c}\text { GERENTES "ALÉM DAS } \\
\text { FRONTEIRAS" }\end{array}$ & \multicolumn{5}{|c|}{ EQUIPE DAS MINI-FÁBRICAS } \\
\hline
\end{tabular}

Figura 4 - Organização matricial de apoio as mini fábricas 
Os indicadores aqui utilizados são, em sua maioria, indicadores de produtividade. AHIRE et al (1996) diz que estes indicadores devem evidenciar a qualidade dos produtos e o cliente. Deste modo, os índices escolhidos foram: reclamações de clientes, custo da qualidade/custo fabricação, atendimento à amostras; a entrega da produção ao estoque, a evolução deste indicador antes e após a estrutura matricial pode ser vista na figura 5, onde pode ser percebido claramente a melhora do índice na fase de utilização da estrutura matricial; o mesmo pode ser visualizado para o indicador quilos bons/horas trabalhadas ( fundição ), refugo por mini fábricas. O gráfico de produtividade da mão de obra da empresa pode ser visto na figura 7 , neste gráfico são levados em conta o absenteísmo e, turn over A evolução do refugo geral é observado na figura 6. As reclamações dos clientes também sofreu um impacto positivo através da utilização da nova estrutura organizacional.

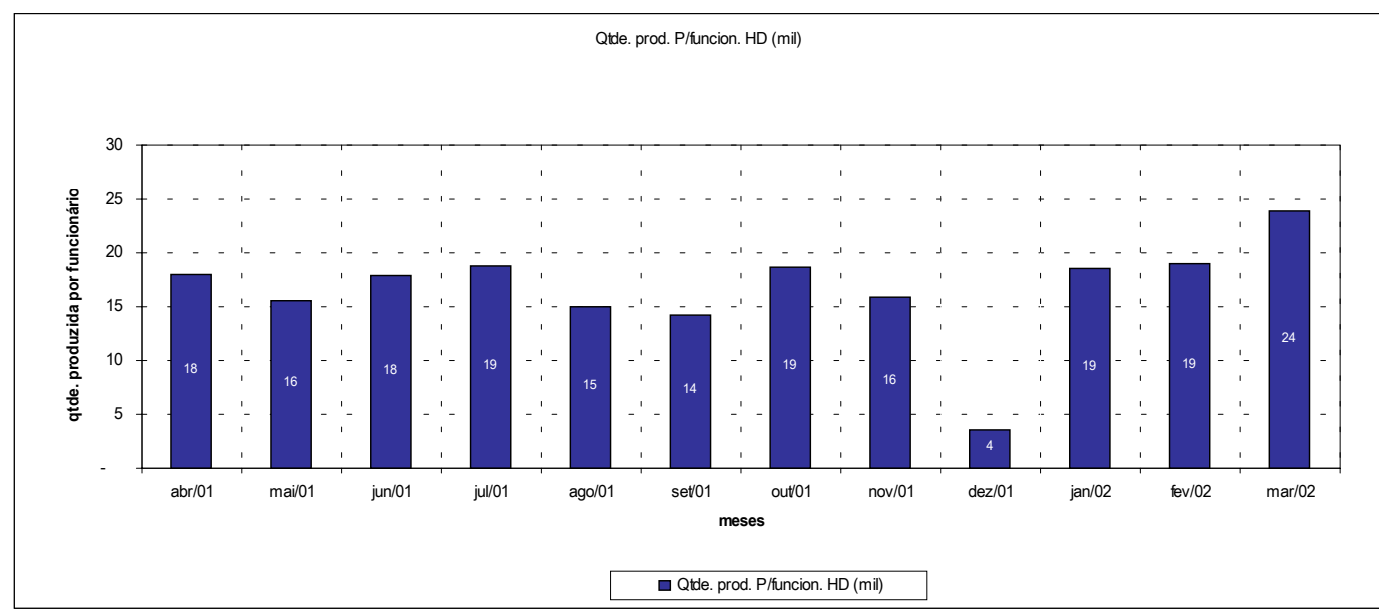

Figura 5 - Evolução da Produtividade antes e após a reestruturação organizacional

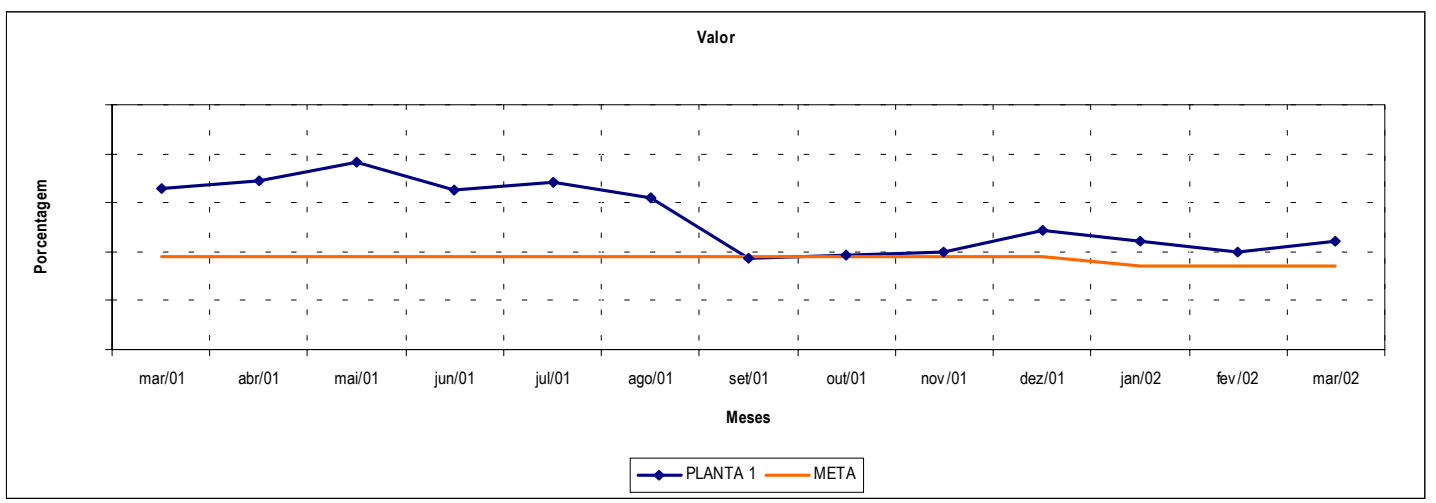

Figura 6 - Evolução do índice de refugo geral

\section{Conclusão}

Segundo afirmam VERGARA e BRANCO (2001) realizar uma mudança organizacional e também cultural em uma grande empresa requer planejamento para preparar e antever as dificuldades de cada etapa do processo e uma forte liderança da alta administração com o apoio da gerência intermediária (neste caso chefia) e foco nas pessoas (colaboradores, clientes, fornecedores e comunidade). Ao longo desta pesquisa, foi possível analisar como a reestruturação organizacional sofre impactos significativos ao se alterar uma das componentes que compõe o sistema produtivo, que neste caso são: recursos humanos, o arranjo físico dos equipamentos e a mudança de visão estratégica da empresa. 
Assim, com base nestes critérios a empresa deve ser avaliada para atingir os objetivos pelos quais se empenha.

Agradecimentos: À empresa que nos forneceu os dados e à Coordenação de Aperfeiçoamento de Pessoal de Nível Superior-CAPES

\section{Bibliografia}

JOHANSON, J. E. Formal structure and intra-organisational networks. An analysis in a combined social and health organisation in Finland. Scandinavian Journal of Management, 2000.

CURY, A.Organização e Métodos:Uma visão Holística. $6^{\text {a }}$ Edição-Revista e Ampliada. Editora Atlas-S.A.São Paulo, 1995.

GHANI, A.K., JAYAKABALAN,V., SUGUMAR, M. Impact of advanced manufacturing technology on organizational structure. The Journal of High Technology Management Research, Elsevier Science, 2002.

YAUCH, C. A., STEUDEL, H. J. Cellular Manufacturing for small business:Key cultural factors that impact the conversion process. Journal of Operations Management, Elsevier Science, 2002.

GONÇALVES, J. E. L. Processo, que Processo? Revista Administração de Empresas RAE - volume 40-páginas 8 a 10, Fundação Getúlio Vargas, São Paulo, Outubro/ Dezembro 2000.

AHIRE, S. L., WALLER, M. A., GOLHAR, D. Y.Quality Management in TQM versus non TQM firms: an empirical investigation. International Journal of Quality Management, Elsevier Science, 1996

ALTAMIRO, A. V. Metodologia para integração do Marketing e da Manufatura. Tese de Doutorado. Universidade Federal de Santa Catarina-UFSC, Florianópolis, 1999

HERNANDEZ, J. M. C., CALDAS, M. P. Resistência a mudança: uma revisão crítica. Revista Administração de Empresas - RAE - volume 41-páginas 31 a 45, Fundação Getúlio Vargas, São Paulo, Abril/ Junho 2001.

KING, A. W., FOWLER, S. W., ZEITHAMI, C. P., Competências organizacionais e vantagem competitiva: $O$ desafio da gerencia intermediária. Revista Administração de Empresas - RAE - volume 42-páginas 36 a 49, Fundação Getúlio Vargas, São Paulo, Janeiro/ Março 2002.

NOORI, H. Implementing advanced manufacturing technology : the perspective of a newly industrialized Country (Malasy).Journal of High Technology Management Research, 1997.

VERGARA, S. C., BRANCO, P. D., Empresa Humanizada: a organização necessária é possível. Revista Administração de Empresas - RAE - volume 41-páginas 20 a 30, Fundação Getúlio Vargas, São Paulo, Abril/ Junho 2001. 